\title{
Stress of the Off-Season May Be Greater for the Student-Athlete than during Competition: A Pilot Study
}

\author{
Jeannie D. DiClementi, Anna Reese, Tyler Borsa \\ Department of Psychology, Indiana University-Purdue University Fort Wayne, Fort Wayne, IN, USA \\ Email: diclemej@ipfw.edu
}

How to cite this paper: DiClementi, J.D., Reese, A. and Borsa, T. (2017) Stress of the Off-Season May Be Greater for the Student-Athlete than During Competition: A Pilot Study. Journal of Behavioral and Brain Science, 7, 304-310.

https://doi.org/10.4236/jbbs.2017.77022

Received: June 1, 2017

Accepted: July 9, 2017

Published: July 13, 2017

Copyright ( 92017 by authors and Scientific Research Publishing Inc. This work is licensed under the Creative Commons Attribution International License (CC BY 4.0).

http://creativecommons.org/licenses/by/4.0/

\begin{abstract}
We assessed 16 student-athletes in their first year of college on several dimensions, including severity of psychological and physical symptoms, mental health upset, academic concerns, suicidal tendencies, depressive outlook, anxiety and tension, attention difficulties, and alcohol abuse. We assessed half during their sports' competition season and half during their off-season. Results pointed to increased perceived stress during the down time of off season. It may be that for student-athletes, the structure of competition season offsets the stress of competition, such that when the structure is removed or lessened, perceived stress increases. Implications of these data are discussed as well as plans for developing follow-up studies.
\end{abstract}

\section{Keywords}

College Student-Athletes, Athletics and Stress, Millon College Counseling Inventory, Student-Athlete Adjustment

\section{Introduction}

Mental illness in athletes (e.g., depressive or anxiety disorders), while likely occurring at a lower prevalence than the general population [1] nevertheless has an important impact on athlete well-being. The demands of athletic training and competition can result in a constellation of problems such as reduced motivation, chronic fatigue, loss of confidence, reduced self-esteem, depression, anxiety, disordered eating, all of which are consistent with both overtraining and major depression. Physicians, trainers, and sports psychologists may confuse depression with overtraining; the result can be inappropriate treatment recommendations [2]. Athletes may be reluctant to admit to mental health problems because of the stigma attached to such admissions, which in turn may be further 
reinforced by treatment providers who misdiagnose them [2].

Previous research reports elevated incidences of depression, anxiety, suicidal ideation, Post Traumatic Stress Disorder (PTSD), and eating and sleep disorders in college students [3]. Miller, et al., [4] reported that 21 per cent of a sample of student athletes had a history of heavy alcohol use; they further pointed to a relationship between depression and alcohol use in athletes, with the alcohol serving a self-medicating function. Burton [5] reports anecdotal evidence of a greater prevalence of Attention Deficit Hyperactivity Disorder (ADHD) among athletes. The author posited that students with ADHD may be drawn to physical activity as a way of dealing with the disorder [5]. Other researchers [6] report a higher incidence of depression among freshmen athletes, in particular females and those with self-reported pain. The emergence of mental illnesses during the ages 18 - 24 has associated with adolescent development, [7] and there appears to be a higher incidence of mental illnesses during this developmental period [7]. In fact, prevalence of mental disorders during this period is higher than for any other age group [7] [8]. For the college student-athlete, this not only could have a significant negative effect on performance, but as discussed [7], frequently results in the student dropping out of college.

Identifying these disorders in athletes, however, may be confounded by the effects of overtraining [2]. Unfortunately, the dichotomous thinking of so-called psychological versus physical illnesses still may be having a deleterious effect on the recognition of treatment of mental disorders in athletes [2]. Further, researchers have pointed to perceived stigma [9] as a barrier to self-identification of difficulties as well as help-seeking for the student-athlete.

Previous attempts to facilitate student transition into college have been somewhat disappointing. Baker [9] had attempted to use a group therapy approach with new college students, conducting psychologist-led group sessions during the first few weeks of the academic year. The author also found that among those students who volunteered for the groups, there were some participants who had no need for the intervention, whereas the numbers of students in need who did volunteer were quite small, given the student population of the University. This, he concluded, pointed to a need to identify students needing intervention [10].

Conley, Travers, and Bryant [11] found some success with psychosocial intervention groups. The authors reported that students in the psychosocial intervention groups showed improvement in psychosocial adjustment over non-participant controls, and that attendance at the group meetings predicted greater positive well-being, less negative distress, and better stress management [11].

Ruberman [7] discusses the benefits of individual psychotherapy to facilitate adjustment to college, particularly in light of the prevalence of mental disorders in this age group. He doesn't, however, address psychotherapy with student athletes and the particular stressors they face in addition to the developmental issues associated with this age group. Others have pointed to the need to educate student-athletes about mental illness, symptoms, treatment and help-seeking [12] as well as educating treatment providers in the unique stressors facing stu- 
dent-athletes [12].

In the current pilot study, we sought to identify sources of distress among student-athletes that may be exacerbated by the stresses of both being athletes and adjusting to college. We wanted to know if student athletes experienced increased stress during their competition season, with resulting depression and/or anxiety. Determining those points in the student-athlete academic and competitive year could contribute to developing specific interventions that could be more efficiently applied during the specific times of the year.

To avoid any possible confounding effects of prior or different experiences with college life or collegiate athletics, we chose to use only first-year studentathletes. We assessed them for not only preexisting mental illnesses, but also for current and preexisting conflicts, stressors, difficult situations and then followed up at two points over the next four months-in competition season and out of season-to measure their levels of perceived stress, anxiety, and depression.

\section{Methods}

For this pilot study, we recruited student-athlete volunteer participants from a National Collegiate Athletic Association (NCAA) Division 1 University athletic department located in the Midwest United States, in the center of a Mental Health Professional Shortage area, [13]. In addition to obtaining Institutional Review Board (IRB) approval, we also received approval from both the Athletics Director and Director of Compliance for the university. All NCAA rules regarding participation in research and compensation for such participation were adhered to. To avoid any appearance of coercion we enrolled only those who volunteered. Sixteen students, twelve female and four male, volunteered.

Participants met individually with a member of the research team. After signing the consent form and being fully informed as to the nature of the study and the study procedures, they were administered the following measures a demographic questionnaire that asked age, race and ethnicity, sport, a clinical interview to screen for preexisting major mental illness, the Millon College Counseling Inventory (MCCI), a 150-item questionnaire that scores 32 profile scales and is designed for use with college students [14] the Brief Symptom Inventory (BSI) a 53-item questionnaire that assesses individuals on several clinical scales, including the number and severity of symptoms endorsed [15]. Half of the student-athletes were evaluated during their competition season $(n=8)$ and half while off season $(n=8)$

We predicted that stress levels would be greater during competition season, resulting in increased indices of distress on the relevant scales of the MCCI and the General Severity Index of the BSI.

\section{Results}

Participants were 16 student-athletes, 12 females and four males from different athletic teams. Mean age was $18.70(\mathrm{SD}=1.07)$. All were in their first year of collegiate athletics. More male-specific sports were already in-season during our 
recruitment, which may explain the lack of male volunteers due to time-limitations and focus on their sports.

We found no diagnosable major mental illness for any of the athletes. During the clinical interview, the athletes talked about difficulties they were having adjusting to the rigorous schedule that included workouts, study tables, team meetings, advisor meetings. Each of the athletes were away from home for the first time, came from small rural communities, and reported they would not be able to afford college without their athletic scholarships.

While the small sample size precluded significant statistical power, we noted some trends. Table 1 shows the differences in the measures between in competition season and out of season. Four of the scales approached significance at the 0.15 confidence level. Specifically, the General Severity Index of the BSI, an indicator of the perceived severity of symptoms reported. The MCCI scales ap-

Table 1. Measures of psychological distress and severity.

\begin{tabular}{|c|c|c|c|c|c|}
\hline Scale & $\mathrm{N}$ & Mean & SD & $\mathrm{F}$ & Significance \\
\hline BSI positive symptom index & & & & 0.805 & 0.386 \\
\hline In season & 8 & 1.06 & 0.63 & & \\
\hline Out of season & 8 & 1.30 & 0.34 & & \\
\hline BSI general severity index & & & & 2.635 & 0.128 \\
\hline In season & 8 & 0.18 & 0.26 & & \\
\hline Out of season & 8 & 0.37 & 0.23 & & \\
\hline MCCI mental health upset & & & & 2.629 & 0.129 \\
\hline In season & 8 & 0.26 & 3.21 & & \\
\hline Out of season & 8 & 9.75 & 11.27 & & \\
\hline MCCI academic concerns & & & & 0.207 & 0.657 \\
\hline In season & 8 & 12.29 & 6.26 & & \\
\hline Out of season & 8 & 11.00 & 4.66 & & \\
\hline MCCI suicidal tendencies & & & & 3.905 & 0.070 \\
\hline In season & 8 & 0.85 & 1.22 & & \\
\hline Out of season & 8 & 4.75 & 5.06 & & \\
\hline MCCI depressive outlook & & & & 2.026 & 0.178 \\
\hline In season & 8 & 3.43 & 4.08 & & \\
\hline Out of season & 8 & 20.88 & 13.25 & & \\
\hline MCCI anxiety//tension & & & & 1.326 & 0.270 \\
\hline In season & 8 & 4.86 & 3.80 & & \\
\hline Out of season & 8 & 7.75 & 5.60 & & \\
\hline MCCI attention deficits & & & & 0.165 & 0.691 \\
\hline In season & 8 & 9.86 & 6.72 & & \\
\hline Out of season & 8 & 11.75 & 10.58 & & \\
\hline MCCI alcohol abuse & & & & 2.395 & 0.146 \\
\hline In season & 8 & 0.85 & 1.57 & & \\
\hline Out of season & 8 & 5.50 & 7.76 & & \\
\hline
\end{tabular}


proaching significance included the Mental Health Upset, Suicidal Tendencies, and the Alcohol Abuse scale.

The General Severity Index of the Brief Symptom Inventory is an indicator of the severity of symptoms endorsed in the BSI. While the students did not report greater numbers of symptoms than the general student population, those that they did endorse were rated as significantly more severe. Student-athletes are typically trained to attend to their physical well-being and may be more sensitive to symptoms as indicators of possible injuries. This tendency may lead to perceptions of greater severity than the symptom warrants.

Also interesting to note is that except for the Academic Concerns Scale of the MCCI, each of the other scales increased in level of distress during the off season for these student-athletes. Thus our hypothesis that distress would be greater during competition season was not supported.

\section{Discussion}

For many of these students, living in relatively isolated rural areas with limited or no access to mental health services, depression and anxiety and other mental conditions likely go unnoticed. Further, in the isolation of rural living in conservative communities as student-athletes, the stigmatization of mental illness is amplified.

Many if not most of our student-athletes come from rural communities, are first-generation college students, and are away from home for the first time. They may or may not be within driving distance from their home communities, but their schedules often prevent trips home. They may be managing their money on their own for the first time. Many are without parental supervision-and support-for the first time.

Students who are accustomed to excelling in high school may find themselves struggling to maintain the same grades and may begin to feel like they are failing. As academic performance begins to decrease, often athletic performance decreases as well. Further, for the student-athlete with a preexisting (to college) psychiatric condition, perceived failure either academically or athletically may further exacerbate the condition. It becomes a downward spiral.

Qualitative data obtained during the clinical interview pointed to common themes among our first-year student athletes: depression, anxiety, career confusion, academic concerns, difficulty adjusting to the schedules, to having roommates, as well as to having most of their lives regimented with classes, study tables, practice, workouts, competitions, travel.

Stigma associated with mental health concerns and treatments is a common phenomenon in the general population, and of particular concern in certain subpopulations, in this case student-athletes [16]. Student-athletes are typically seen as healthy, fit, and well-functioning; any suggestion that an athlete may have a mental health issue is frequently minimized, ignored, or seen as a sign of weakness. Sports psychologists working with student-athletes focus on issues of motivation, performance, attitude, and generally do not address clinical issues 
such as depression, anxiety, reaction to stress, and the like. Consequently, it is reasonable to assume that many student-athletes with such issues are undiagnosed and untreated.

At the same time, student-athletes face a wide range of challenges in college as they balance practices, meetings, competitions, travel, classes, homework, exams, and some sort of social life. They come to college with coping abilities that range from none to effective. Add to that family pressures, injuries, and other stressors, and the result may be a distressed athlete.

While the current study does not support our hypothesis that emotional distress increases with the stressors associated with competition season, it may be that the structure inherent in the collegiate competition season may paradoxically provide support for the student-athlete, such that in the off season with the decrease in demands, the athletes may find themselves floundering and feeling isolated and insecure. Depression and anxiety may then set in.

Results of the current study are limited due to the small sample size and the unique setting of a regional, multi-university campus. Although there were several sports represented in our sample, our athletes all follow nearly identical schedules divided among conditioning, practice, competing, classes, advising, and study time. Nevertheless it remains to be seen if there are between-sport differences, between-gender differences or even differences between leagues.

Gavrilova, Donohue, and Galante [17] recommend that athletic programs ensure that student athletes receive mental health screening, work to reduce the stigma associated with mental illness, and hire licensed clinical and counseling psychologists to provide assessment and evidence-based intervention programs. We are currently developing a prospective study to identify risk factors for our student-athletes prior to their freshmen year. The measure being developed will be distributed to each incoming student-athlete in the summer before their freshman year and will provide information about the students' prior experiences, depression, anxiety, coping strategies, living situations, support systems. Student-athletes will be assessed by a trained staff supervised by a licensed clinical psychologist. With the information, we will then follow the new cohort of student athletes throughout the year and will be able to target specific stressors and apply relevant interventions.

\section{Acknowledgements}

The authors thank Kelley Hartley Hutton, Wendy Wilson, and Christine Kuznar of the Fort Wayne Department of Athletics for their support of this study.

\section{References}

[1] Sime, W.E. (1987) Exercise in the Prevention and Treatment of Depression. In: Morgan, W.P. and Goldston, S.E., Eds., Exercise and Mental Health, Hemisphere Publishing, New York, 145-153.

[2] Schwenk, T.L. (2000) The Stigmatisation and Denial of Mental Illness in Athletes. British Journal of Sports Medicine, 34, 4-5. https://doi.org/10.1136/bjsm.34.1.4 
[3] Unwin, B.K., Goode, J., Reamy, B.V. and Quinlan, J. (2013) Care of the College Student. American Family Physician, 88, 596-607.

[4] Miller, B.E., Miller, M.N., Verhegge, R.., et al. (2002) Alcohol Misuse among College Athletes: Self-Medication for Psychiatric Symptoms? Journal of Drug Education, 32, 41-52. https://doi.org/10.2190/JDFM-AVAK-G9FV-0MYY

[5] Burton, R.W. (2000) Mental Illness in Athletes. In: Begel, D. and Barton, R.W., Eds., Sports Psychiatry, WW Norton and Company, Inc., New York, 61-81.

[6] Yang, J., Peek-Asa, C., Corlette, J.D., Cheng, G., Foster, D.T. and Albright, J. (2007) Prevalence of and Risk Factors Associated with Symptoms of Depression in Competitive Collegiate Student Athletes. Clinical Journal of Sports Medicine, 17, 481487. https://doi.org/10.1097/JSM.0b013e31815aed6b

[7] Ruberman, L. (2014) Challenges in the Transition to College: The Perspective of the Therapist Back Home. American Journal of Psychotherapy, 68, 103-115.

[8] Kessler, R.C., McGonagle, K.A., Zhao, S., Nelson, C.B., Hughes, M., Eshleman, S., Wittchen, H.U. and Kendler, K.S. (1994) Lifetime and 12-Month Prevalence of DSM-III-R Psychiatric Disorders in the United States: Results from the National Comorbidity Study. Archives of General Psychiatry, 51, 8-19. https://doi.org/10.1001/archpsyc.1994.03950010008002

[9] Kaier, E., DeMarni, C.L., Johnson, M.D., Strunk, K. and Davis, J.L. (2015) Perceptions of Mental Illness Stigma: Comparisons of Athletes to Non-Athlete Peers. Journal of College Student Development, 56, 735. https://doi.org/10.1353/csd.2015.0079

[10] Baker, R.W. and Nisenbaum, S. (1979) Lessons from an Attempt to Facilitate Freshman Transition into College. Journal of American College Health Association, 28, 79-81. https://doi.org/10.1080/01644300.1979.10392898

[11] Conley, C.S., Travers, L.V. and Bryant, F.B. (2013) Promoting Psychosocial Adjustment and Stress Management in First-Year College Students: The Benefits of Engagement in a Psychosocial Wellness Seminar. Journal of American College Health, 61, 75-86. https://doi.org/10.1080/07448481.2012.754757

[12] Glick, I.D. and Horsfall, J.L. (2009) Psychiatric Conditions in Sports: Diagnosis, Treatment, and Quality of Life. The Physician and Sports Medicine, 37, 29-37. https://doi.org/10.3810/psm.2009.10.1726

[13] Indiana State Department of Health. http://www.in.gov/isdh/files/mhpsa_0414.pdf

[14] Millon, T., Strack, S.N., Millon, C. and Grossman, S. (2006) Millon College Counseling Inventory Manual. Pearson, Minneapolis.

[15] Derogatis, L.R. (1993) Brief Symptom Inventory Manual. Pearson, Minneapolis.

[16] Reardon, C.L. and Factor, R.M. (2010) Sports Psychiatry: A Systematic Review of Diagnosis and Medical Treatment of Mental Illness in Athletes. Sports Medicine, 40, 961-980. https://doi.org/10.2165/11536580-000000000-00000

[17] Gavrilova, Y., Donohue, B. and Galante, M. (2017) Mental Health and Sport Performance Programming in Athletes Who Present Without Pathology: A Case Examination Supporting Optimization. Clinical Case Studies, 16, 234-253. https://doi.org/10.1177/1534650116689302 
Submit or recommend next manuscript to SCIRP and we will provide best service for you:

Accepting pre-submission inquiries through Email, Facebook, LinkedIn, Twitter, etc. A wide selection of journals (inclusive of 9 subjects, more than 200 journals)

Providing 24-hour high-quality service

User-friendly online submission system

Fair and swift peer-review system

Efficient typesetting and proofreading procedure

Display of the result of downloads and visits, as well as the number of cited articles Maximum dissemination of your research work

Submit your manuscript at: http://papersubmission.scirp.org/

Or contact jbbs@scirp.org 